Article

\title{
Improving the Tribological Properties of Technical Polymers with Metal Sulphide Compounds
}

\author{
Andreas Hausberger ${ }^{1, *(\mathbb{D}}$, Tanja Stiller ${ }^{1}\left(\mathbb{D}\right.$, Clemens Kappl $^{2}$, Lars Hensgen $^{2}$ and Florian Grün ${ }^{3}(\mathbb{D}$ \\ 1 Polymer Competence Center Leoben GmbH, Roseggerstraße 12, 8700 Leoben, Austria; tanja.stiller@pccl.at \\ 2 Tribotecc GmbH, Industriestrasse 23, 9601 Arnoldstein, Austria; clemens.kappl@tribotecc.com (C.K.); \\ lars.hensgen@tribotecc.com (L.H.) \\ 3 Institute of Mechanical Engineering, Montanuniversitaet Leoben, Franz Josef-Straße 18, 8700 Leoben, Austria; \\ florian.gruen@unileoben.ac.at \\ * Correspondence: andreas.hausberger@pccl.at; Tel.: +43-3842-42962-36
}

check for

updates

Citation: Hausberger, A.; Stiller, T.; Kappl, C.; Hensgen, L.; Grün, F. Improving the Tribological Properties of Technical Polymers with Metal Sulphide Compounds. Lubricants 2021, 9, 91. https://doi.org/ 10.3390/lubricants 9090091

Received: 30 July 2021

Accepted: 2 September 2021

Published: 13 September 2021

Publisher's Note: MDPI stays neutral with regard to jurisdictional claims in published maps and institutional affiliations.

Copyright: (c) 2021 by the authors. Licensee MDPI, Basel, Switzerland. This article is an open access article distributed under the terms and conditions of the Creative Commons Attribution (CC BY) license (https:/ / creativecommons.org/licenses/by/ $4.0 /)$.

\begin{abstract}
Technical thermoplastic materials (e.g., PEEK, PPA and POM) are widely used for tribological applications combined with different filler systems (e.g., glass- or carbon fibres) because of their excellent mechanical properties. The friction and wear behaviour of thermoplastics can be specifically improved by solid lubrication systems such as graphite, PTFE and $\mathrm{MoS}_{2}$. Besides these systems, others such as $\mathrm{WoS}_{2}$ and MnS are becoming scientifically interesting. This work investigates the influence of different solid lubricants-alternative metal sulphides and polymer-based-in combination with different glass fibre contents on the tribological behaviour of unfilled PEEK and glass fibre-filled PPA. For this purpose, compounds were produced and injection-moulded into tribological test specimens that were subsequently tested. It is particularly evident for both matrix materials that the solid lubricant SLS 22 shows a 25\% wear rate reduction when compared to $\mathrm{MoS}_{2}$ and, in addition, the proportion of fibre content in PPA shows an additional wear rate reduction by a factor of 10 . The friction level could be kept at a similar level compared to the usually utilised solid lubricants. The investigations showed the potential use of metal sulphide filler systems in high-performance thermoplastic with enhanced tribological properties as alternatives to the well-established solid lubricants.
\end{abstract}

Keywords: metal sulphide; PEEK; PPA; glass fibre; solid lubricant; friction and wear

\section{Introduction}

The occurrence of friction remains mostly unnoticed, but it has a huge impact on our daily life. In the private sector as well as in industry, friction can be either a pleasant or an unwelcome factor. For moving parts in furniture or bearings made of polymers, high friction is undesired, whereas, for instance, in emergency brake cases high friction is absolutely required [1-4]. An undesired friction level for a certain application can cause high energy consumption as, for example, in requiring cooling systems due to the generated frictional heat. Further problems can occur in the case where high friction causes high wear, resulting in unavoidable maintenances to replace components [1-3]. Therefore, an optimized material selection for a specific tribological application will result in a product with better performance and a longer lifetime.

One possible way to achieve both desired friction values and low wear is the usage of filler or reinforcing materials [1-3,5-9]. In the beginning of "filler history", by-products or cheap materials were used as fillers, which, by coincidence, had a reinforcing effect in polymers. After more detailed investigations on the aspect ratio and on the structure of fillers, it turned out that these were major influence factors for good or bad performance of the filler [7,9-12]. Besides the possibility of using liquids as lubricants, nowadays it is also common to use solid lubricants, which are incorporated in the material [2,6-9]. In 1986, Friedrich et al. discussed in detail the influence of fillers and fibres on the wear [1]. 
Their studies are the basis for recent developments in tribologically optimized material compounds. The most well-known solid lubricants in polymers are PTFE, $\mathrm{MoS}_{2}$ and graphite, which consist of a layered structure with strong intralayer but weak interlayer bonds. During an applied shearing force, the layers separate and form sliding layers on both components with low friction [1-3,5,6,8,9]. A common way to improve overall properties is to compound a mixture of fillers, such as fibres (glass or carbon) and solid lubricants (PTFE, $\mathrm{MoS}_{2}$ and graphite). However, the combination of two or more fillers does not always show the desired effect of enhancing properties [13-19].

Furthermore, material processing plays an important role when tribological behaviour is considered. For fibre-reinforced materials, a parallel or perpendicular arrangement of the fibres is ideal for mechanical and tribological properties. Injection moulding causes no clear orientation of the fibres because of the fountain flow of the molten material, which flows between frozen-edged surfaces. Due to the rapid cooling of edge layers, the fibres are oriented in an unfixed angle or, in some cases, a layer with a very low fibre content can occur $[1,7,20-23]$. Nevertheless, there is still an observable difference in the arrangements of the fibres depending on sampling position of the specimen, which indeed has an impact on the friction and wear behaviour.

The objective of this work is to investigate the general tribological performance of metal sulphides and study in detail the interaction between solid lubricant, glass fibres and matrix material. Filler systems do not work properly with every matrix material, which has to be considered if new compounds are produced [18,19,24].

\section{Materials and Methods}

\subsection{Matrix Materials and Filler Systems}

The matrix materials Polyetheretherketone (PEEK, VESTAKEEP 4000G, Evonik Industries AG, Essen, Germany) and Polyphthalamide (PPA, Zytel, DuPont de Nemours, Wilmington, Delaware., USA) with $15 \%$ and $30 \%$ glass fibre content, were compounded with seven different solid lubricants. The basic mechanical and thermal properties for the reference materials are listed in Table 1 . These data were gathered from the supplier datasheets and should act as basic indicators.

Table 1. Summary of mechanical and thermal properties of the matrix materials PEEK, PPA GF15 and PPA GF30.

\begin{tabular}{cccc}
\hline Property & PEEK & PPA GF15 & PPA GF30 \\
\hline Tensile modulus (ISO 527), $\mathrm{MPa}$ & 3500 & 6500 & $8700-11500$ \\
Tension at break (ISO 527), $\mathrm{MPa}$ & 96 & 120 & $165-215$ \\
Ball impression hardness, $\mathrm{MPa}$ & 253 & 200 & 225 \\
Glass transition temperature, ${ }^{\circ} \mathrm{C}$ & 152 & 135 & 125 \\
Melting temperature, ${ }^{\circ} \mathrm{C}$ & 340 & 300 & 320 \\
Long-term service temperature, ${ }^{\circ} \mathrm{C}$ & 260 & 140 & 150 \\
Heat conductivity, $\mathrm{W} / \mathrm{mK}$ & 0.27 & 0.31 & 0.34 \\
Density, $\mathrm{g} / \mathrm{cm}^{3}$ & 1.3 & 1.3 & $1.42-1.45$ \\
\hline
\end{tabular}

In Table 2, the fillers are listed with their respective particle sizes $\left(D_{50} \& D_{90}\right)$ and densities. All solid lubricants based on metal sulphides were developed, measured and kindly provided by Tribotecc $\mathrm{GmbH}$ (Arnoldstein, Austria). All metal sulphide solid lubricants have a platelet structure forming a layered lattice structure as visible in the picture in Table 2. The polymer-based solid lubricants (PTFE and PE-UHMWPE) were measured and kindly provided by Avient (Gaggenau, Germany), and have a spherical shape. 
Table 2. Filler systems with their detailed description, particle size and density; SEM picture showing the principle lattice structure of metal sulphide solid lubricants.

\begin{tabular}{|c|c|c|c|c|c|}
\hline & Filler System & Description & $\begin{array}{l}\mathrm{D}_{50} \\
{[\mu \mathrm{m}]}\end{array}$ & $\begin{array}{l}D_{90} \\
{[\mu \mathrm{m}]}\end{array}$ & $\begin{array}{l}\text { Density } \\
{\left[\mathrm{g} / \mathrm{cm}^{3}\right]}\end{array}$ \\
\hline \multirow{7}{*}{ SEM MAG: 15 KK } & MOS XF & $\begin{array}{l}\text { Natural molybdenum disulphide } \\
\text { grade }\end{array}$ & 10 & 23 & 4.8 \\
\hline & SLS 22 & $\begin{array}{c}\text { New synthetic lubricant system } \\
\text { based on phosphates and tin } \\
\text { sulphides }\end{array}$ & 8 & 24 & 3.1 \\
\hline & SLS 22F & $\begin{array}{c}\text { New synthetic lubricant system } \\
\text { based on phosphates and tin } \\
\text { sulphides }\end{array}$ & 3 & 9 & 3.1 \\
\hline & WS 2 & $\begin{array}{l}\text { Pure synthetic tungsten disulphide } \\
\text { grade }\end{array}$ & 3 & 7 & 7.5 \\
\hline & WS 31 & $\begin{array}{l}\text { New synthetic multiphase-sulphide } \\
\text { based on Mo and W }\end{array}$ & 6 & 15 & 8 \\
\hline & PTFE & Polytetrafluorethylene & - & - & 2.2 \\
\hline & PE-UHMW & $\begin{array}{l}\text { Ultra-high molecular weight } \\
\text { Polyethylene }\end{array}$ & - & - & 1.0 \\
\hline
\end{tabular}

\subsection{Sample Preparation}

For the tribological investigations, injection moulded tensile test specimens were further processed into tribological test specimens with a cross-section area of $4 \times 4 \mathrm{~mm}^{2}$ using a CNC milling machine. To prevent contamination of the running surface, no lubricants or coolants were used. In this work, the focus also lies on the influence of the fibre orientation in the skin layer from the injection moulding process; therefore, two different orientations were chosen for the samples, namely in processing direction (IPD) and normal to the processing direction (NTPD) (see Figure 1).

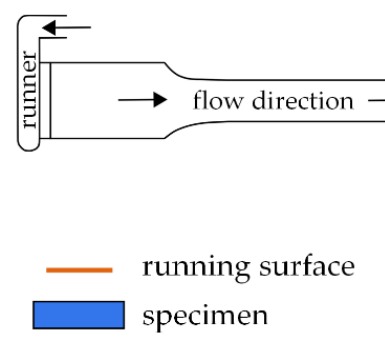

(a)

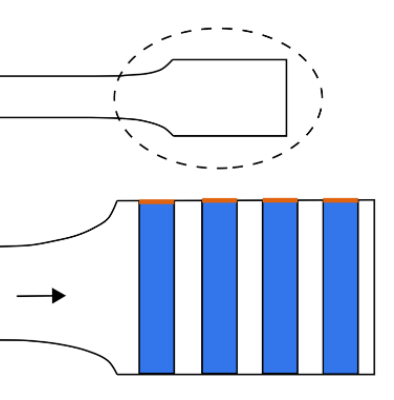

NTPD

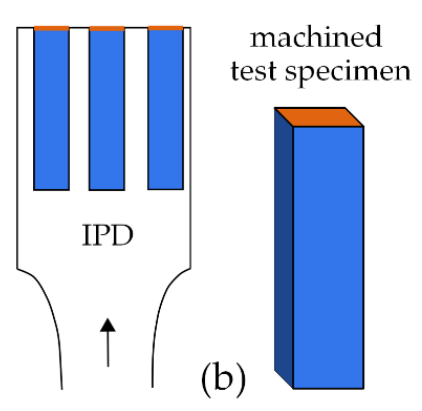

Figure 1. Sampling position of the tribological specimen at the tensile dumbbell (a) and machined test specimen $(\mathbf{b})$.

\subsection{Thermal Properties}

For selected materials (SLS 22 grades), the heat conductivity of the injection moulded samples was measured with a Hot Disk instrument (Hot Disk TPS 2500S Thermal Constants Analyzer, Hot Disk AB, Haar, Germany).

\subsection{Tribological Properties}

For this study, a Pin on Disc (PoD) test setup was chosen and performed with a Universal Mechanical Tester UMT-2 from Bruker (Bruker Nano Surfaces Division, Campell, CA, USA) (see Figure 2a). The counterpart discs for all tests were made out of 34CrNiMo6 steel with an average roughness of Ra $0.3 \mu \mathrm{m}$ which was determined according to DIN EN ISO 25178 using a confocal light microscope MicroProf ${ }^{\circledR}$ (Fries Research \& Technology $\mathrm{GmbH}$, Bergisch Gladbach, Germany) [25]. All samples were investigated with the same testing parameters, namely a normal load of $2 \mathrm{MPa}$ with a rotational speed of $1 \mathrm{~m} / \mathrm{s}$ for $4 \mathrm{~h}$. 
This test duration ensures that the coefficient of friction plateau was reached and that the running-in phase turned into a steady friction state. For all tests, at least 2 repetitions were conducted and in Figure $2 b$, an example of the coefficient of friction (CoF) evolution and data processing is described. The wear rate was calculated by the volumetric mass loss (mass loss/density) in relation to the applied load and distance travelled.

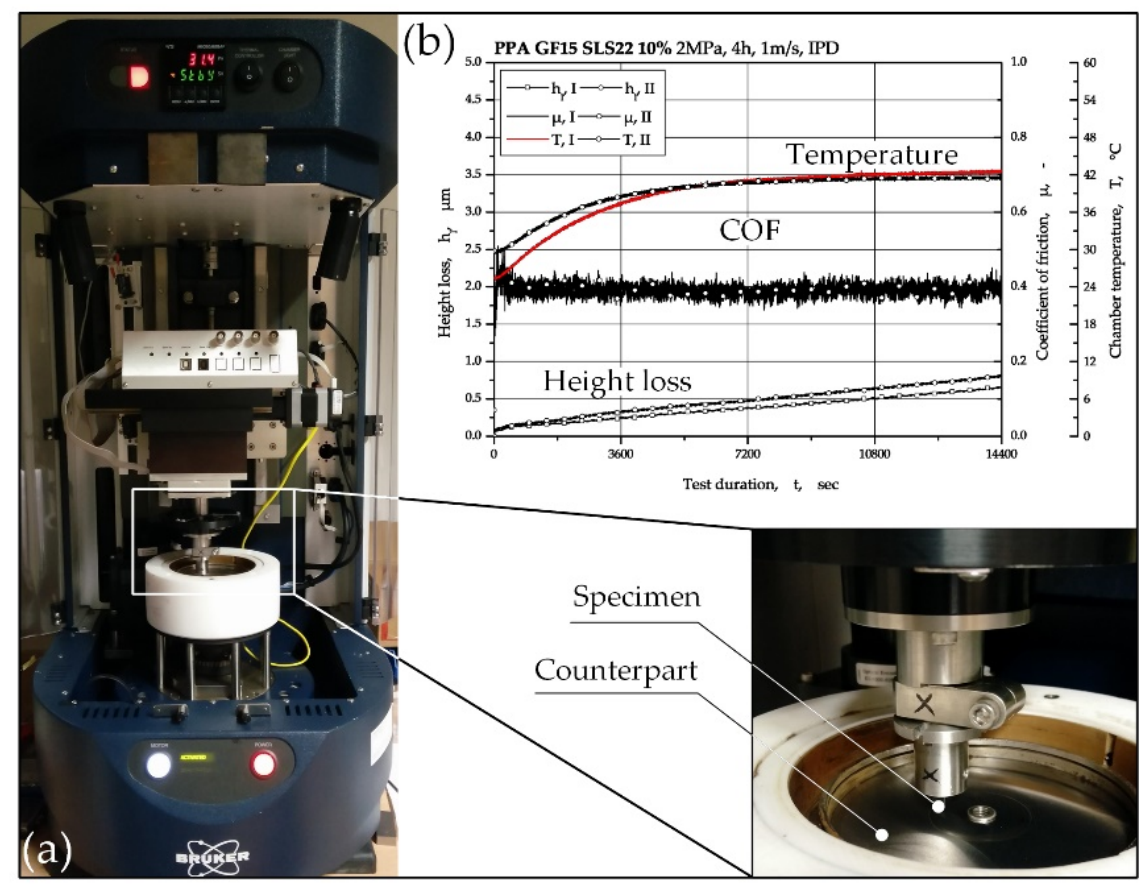

Figure 2. Tribological measurement system (UMT-2) with PoD setup (a) and an example for the evolution of the $\mathrm{CoF}$ and data processing $(\mathbf{b})$.

\subsection{Damage Analysis}

For all tested samples and the corresponding counterpart, a damage analysis of the running surfaces was conducted with an Olympus SZX 12 light microscope (Olympus IMS, Tokio, Japan). The samples were analysed with a magnification of $20 \times, 40 \times$ and $90 \times$ and a representative selection will be shown in the result section. For an in-depth damage analysis, SEM (scanning electron microscope) and EDX (energy dispersive x-ray spectroscopy) pictures were taken on a Tescan inaX-act microscope (EO Elektronenoptik Service GmbH, Dortmund, Germany).

\section{Results and Discussion}

\subsection{PEEK + 10 wt.\% Metal Sulphide Solid Lubricants}

The results from the investigations of PEEK give a first insight for $10 \mathrm{wt} \%$ metal sulphide filler systems and their impact on an unfilled PEEK depending on the specimen orientation. In Figure 3, the wear rates and the coefficients of friction (CoF) are given parallel (in processing direction, IPD) and perpendicular (normal to processing direction, NTPD) to the injection moulding direction.

Unfilled PEEK presented wear rate values for both positions into the range of 2.0 to $2.27 \times 10^{-8} \mathrm{~cm}^{3} / \mathrm{Nm}$ and a CoF around 0.5. The small differences of the neat PEEK are negligible. Comparing these values to the ones with metal sulphide filler systems, MOS XF, SLS 22 and SLS 22F, an enormous decrease (1/3 to 1/10) in the wear rate is shown. The extremely low wear rate for SLS 22 reaches a minimum for the samples NTPD with a value of $0.12 \times 10^{-8} \mathrm{~cm}^{3} / \mathrm{Nm}$. The CoF of SLS 22 parallel sample is even higher than the one for the unfilled PEEK. The finer version of SLS 22, namely SLS 22F, shows comparable values for both sampling positions regarding the CoF value. This could be traced back to the finer particle size (cp. Table 2) especially for D90 with a difference of $15 \mu \mathrm{m}$ when compared 
to SLS 22. Smaller particles could be better distributed within the matrix and could also reach the surface of the part more easily than bigger particles [12,26-28]. The observations further indicate that both WS-types show a dependence on the sampling position for the wear rate. Perpendicular samples (NTPD) wear more than the ones parallel to the injection moulding direction (IPD). In Figure 4, both WS 2 and WS 31 running surfaces show a different wear pattern for IPD compared to NTPD, namely similar to oil-stains-coloured running tracks. This could be an indication of the lubricant, which was better distributed over the surface compared to the NTPD sample.

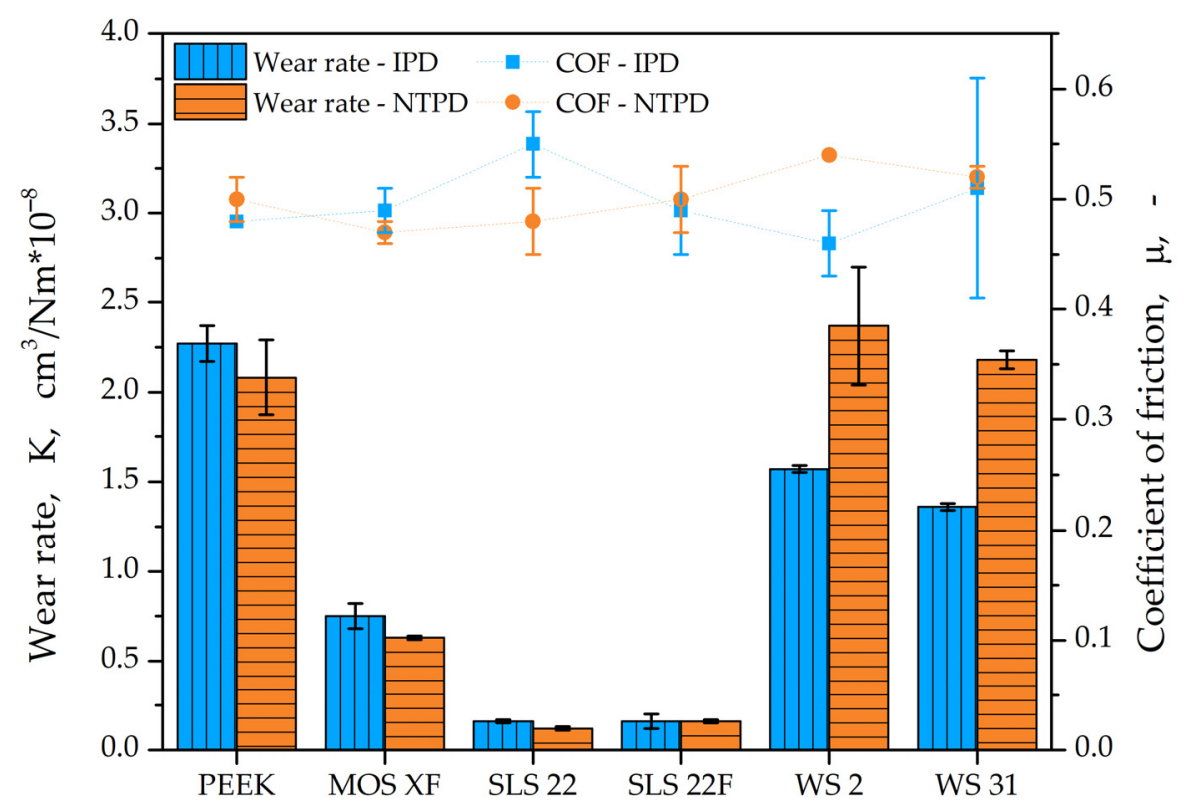

Figure 3. Wear rates and coefficients of friction for PEEK and metal sulphide filler systems parallel (IPD) and normal to the processing direction (NTPD).

In general, the values for $\mathrm{CoF}$ and wear rate of metal-sulphide-filled samples seem to correlate-a higher friction leads to higher wear rates. Nevertheless, for WS 31, the wear rates differ even though the mean value of the $\mathrm{CoF}$ is the same but the standard deviation is significantly higher in IPD.

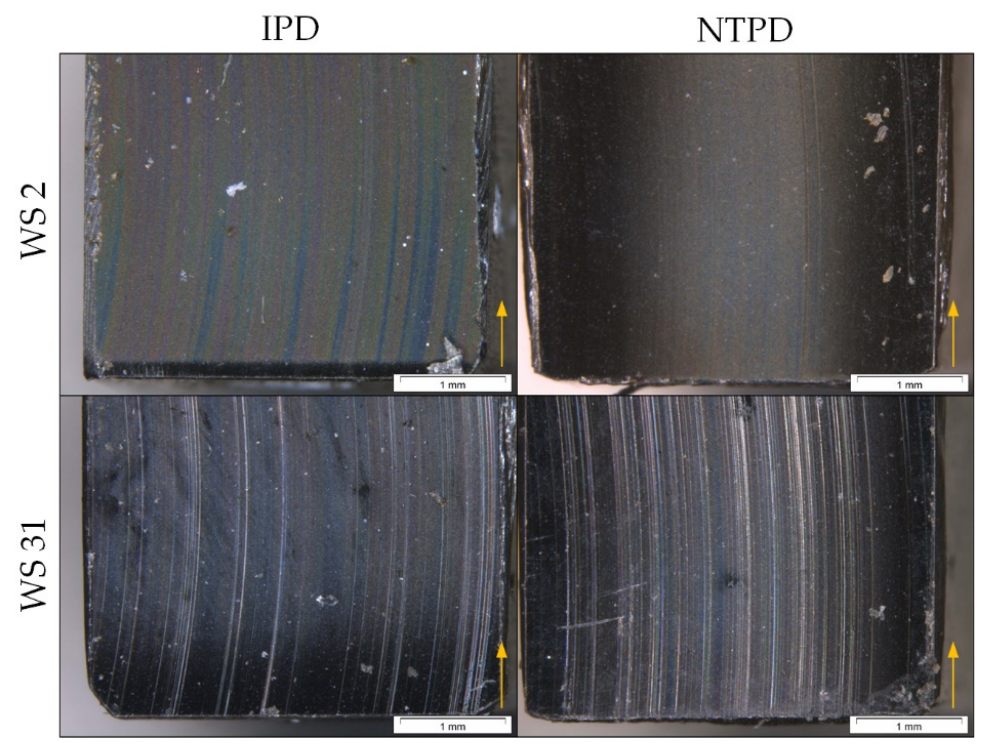

Figure 4. Running surface of WS 2 and WS 31 for both sampling directions, showing a different surface appearance with a magnification of $40 \times$ for all pictures. Arrows indicate the moving direction. 


\subsection{PPA GF15 with Different Filling Degrees of Metal Sulphide Solid Lubricants}

After the promising results with PEEK, another matrix material was chosen to determine the influence of the filling degrees, i.e., $5 \mathrm{wt} . \%$ and $10 \mathrm{wt} . \%$, on the tribological values for a $15 \mathrm{wt} . \%$ glass-fibre-reinforced PPA. The specimens were tested parallel (IPD) and normal to the processing direction (NTPD) and the results are summarized in Figure 5.

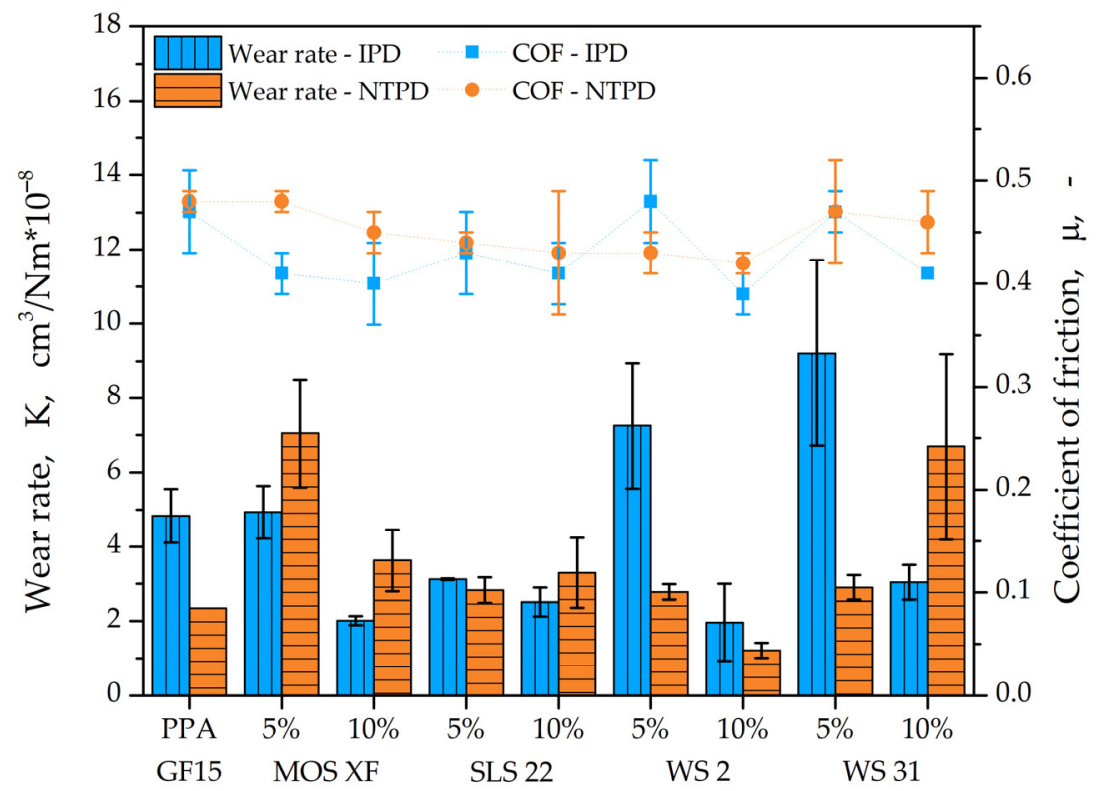

Figure 5. Wear rates and coefficients of friction for PPA GF15 and metal sulphide filler systems with different filling degrees in (IPD) and normal to the processing direction (NTPD).

The diagram (Figure 5) shows at first sight that a lower filling degree leads to higher wear rates for almost all materials, besides SLS 22, which presents similar wear rates for both filling degrees, and WS 31, which shows the exact opposite trend for a higher filling degree and the perpendicular-to-processing samples. Investigating the $15 \mathrm{wt} . \%$ glass-fibrereinforced PPA without a solid lubricant, a dependence on the sampling position for the wear rates is observed, but not for the friction coefficient. In general, the wear rates for PPA samples are higher than for PEEK-matrix samples, which can be traced back to the tribological behaviour of PEEK (cp. Figure 3). On the other side, the coefficient of friction for all compounds is a bit lower than the values for PEEK. It appears that independent of the filling degree or sampling position, the CoF is either the same as the neat PPA GF15 or lower. For MOS XF, the CoF apparently depends on the sampling position for both filling degrees, whereas for SLS 22, the CoF does not change to a noteworthy extent.

Considering the wear rate values below $3 \times 10^{-8} \mathrm{~cm}^{3} / \mathrm{Nm}$, the samples MOS XF $10 \%$, both SLS 22, WS $210 \%$ and partly WS 31 show a comparable wear rate to PEEK (cp. Figure 3 with the values of 2.0 to $2.27 \times 10^{-8} \mathrm{~cm}^{3} / \mathrm{Nm}$ ). The generally higher standard deviations could be evoked by the glass fibre reinforcements, which have an influence on the build-up process of the transferred film on the counterparts $[1,5,29,30]$. If the glass fibres act more abrasively, the film will be removed more easily, which results in higher wear due to new transforming processes. This can be seen in Figure 6, which compares the damage pictures of the running surface and the wear track on the counterpart of WS 2 IPD for both filling degrees.

The glass fibres seem to have an impact on lower filling degrees for WS-compounds. It is possible to observe that glass fibres are visible only for the 5\% filled samples (surface specimen). Moreover, there is a remarkable material transfer to the counterpart for these samples. Due to the dynamic formation of the material film, the track can be peeled off and form long wear particles, as obviously shown in Figure 6 (bottom left). Comparing this to the same material but with a higher filling degree, the solid lubricant forms a gliding 
layer which shows almost no glass fibres on the surface. Furthermore, the track on the counterpart looks homogenous without accumulation of material.

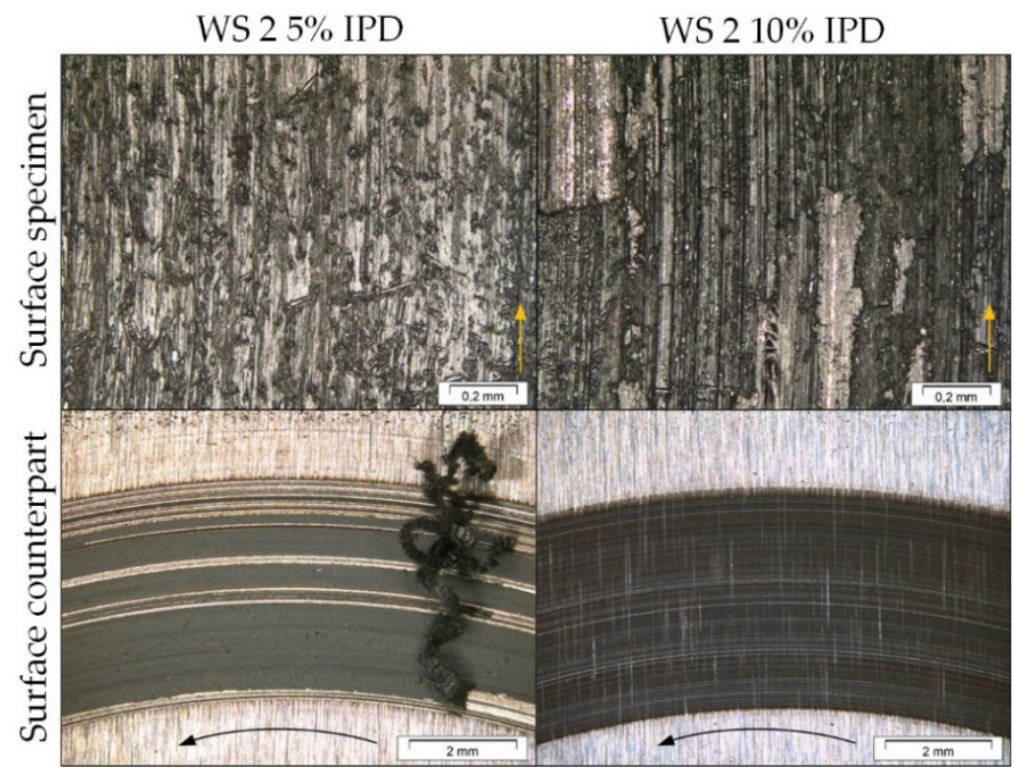

Figure 6. Light microscopic analysis of the running surface $(100 \times)$ and the counterparts $(7 \times)$ for WS 2 for both filling degrees in processing direction. Arrows indicate the moving direction.

This clear trend in the damage analysis is also given for SLS 22, as exemplarily shown in Figure 7. The sample with the 5\% filler shows less material transfer to the counterpart and also a lower deviation in the wear rate than the $10 \%$ sample. For this metal sulphide lubricant, the glide layers are also visible in Figure 7.

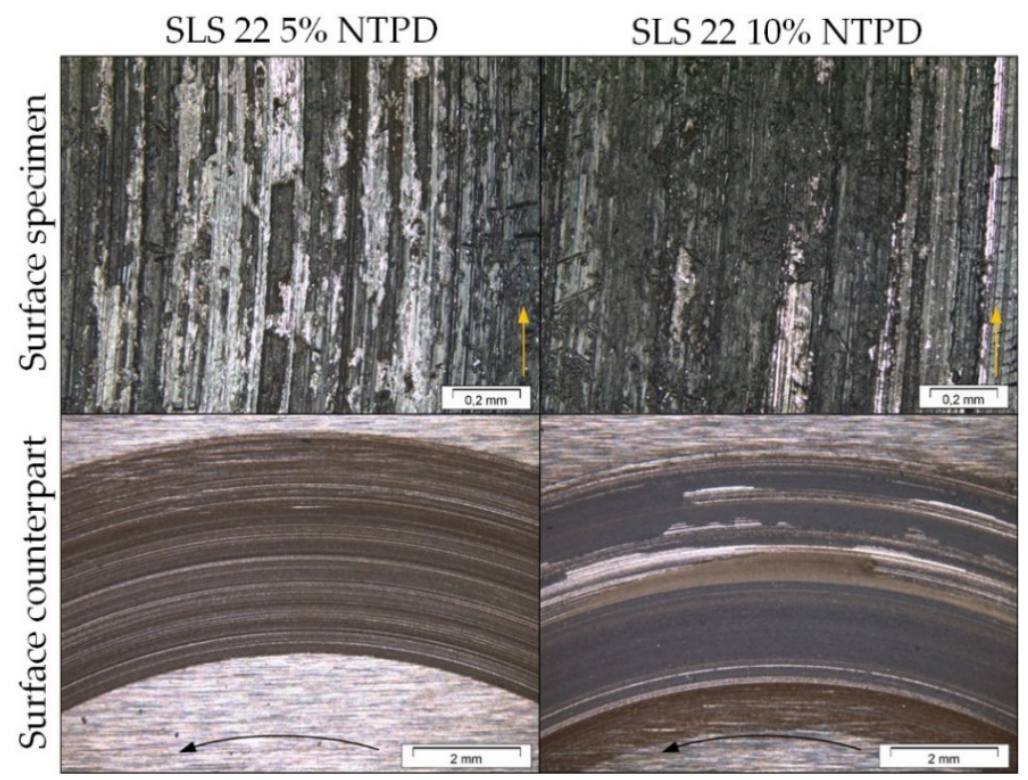

Figure 7. Light microscopic analysis of the sample running surface $(100 \times)$ and the counterparts $(7 \times)$ for SLS 22 for both filling degrees normal to the processing direction. Arrows indicate the moving direction.

In order to have a closer look at the fibres' orientation after the test, samples normal to the processing direction with a $10 \%$ filling degree were investigated in SEM/EDX to gain qualitative information about the fibres. In Figure 8, pictures with the stacked mapping of the elements are shown. 
In the neat PPA GF15 reference EDX micrograph, the orientation of the fibres is not entirely in one direction, but is mostly aligned parallel to the running surface. The detected elements, such as aluminium (Al), calcium (Ca), silicon ( $\mathrm{Si})$, magnesium $(\mathrm{Mg})$ and oxygen (O), are typical for glass fibres [31-34]. For all EDX micrographs (see Figure 8), the colour pattern of the fibres depicts worn glass fibres that accumulate in the area of the matrixincorporated fibres [15,17,35]. Moreover, Figure 8 shows a smooth distribution of fillers. Interestingly, SLS 22 formed a kind of plateau with a destroyed area, which reveals many glass fibres. A similar picture is given for WS 31, but here, the region on the right represents an already worn material transferred back from the counterpart to the specimen surface. An indication of this is the detected iron (Fe), which could only be attributed to the metallic counterpart since the filler systems do not contain any form of iron.

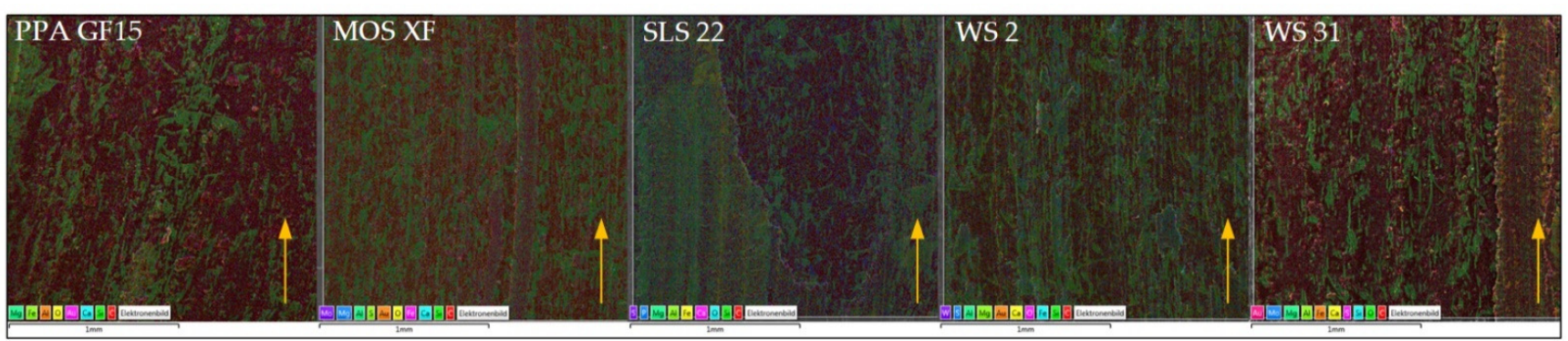

Figure 8. EDX micrographs $(100 \times)$ of all PPA GF15 systems with a $10 \%$ filling degree and a sampling position normal to the processing direction. Arrows indicate the moving direction.

\subsection{PPA GF30 with Different Solid Lubricants}

Based on the promising results from SLS 22 for both filling degrees (see Section 3.2), a PPA with $30 \mathrm{wt} . \%$ glass fibre reinforcement is compared to common polymeric solid lubricants, such as PTFE and PE-UHMW. In order to investigate the influence of the SLS $22 \mathrm{~F}$ filling degree, a third value, namely $8 \mathrm{wt} . \%$, was tested in the same conditions as the other previously discussed test series. The results are shown in Figure 9. Due to the obtained information about test stability and standard deviations regarding the influence on the sample direction in Section 3.2, for this test series the sample orientation was only considered in processing direction.

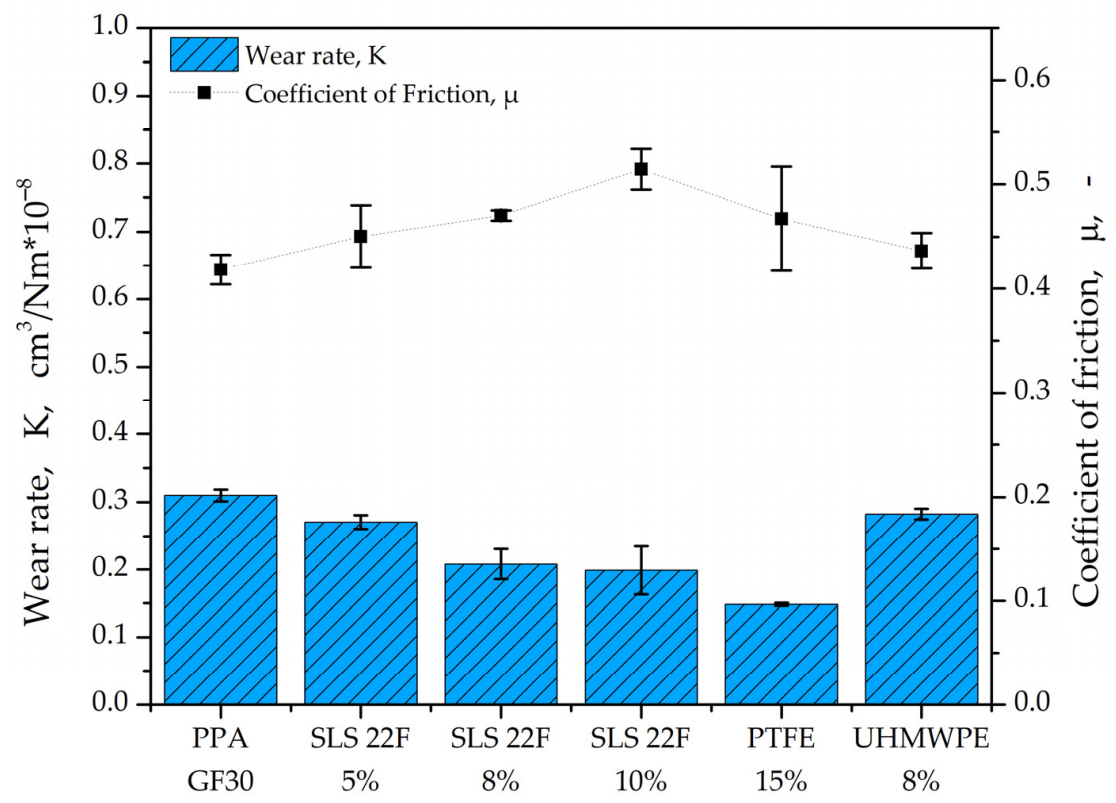

Figure 9. Wear rates and coefficients of friction for neat PPA GF30 and filled samples with metal sulphide or polymeric filler systems. 
The CoF increases not only with the SLS 22F filler content, but also with the addition of polymeric solid lubricants. In contrast, the wear rates can be reduced by all filler systems. The wear rate decreases with the increase in the SLS 22F filling degree. Moreover, the addition of the $15 \%$ PTFE causes an even lower $(-10 \%)$ wear rate value when compared to a $10 \%$ addition in SLS 22F. Nevertheless, it should be mentioned that PTFE is present with $15 \mathrm{wt} . \%$ and therefore more lubricant is available than for all the other samples. Figure 10 displays a visual analysis of the running surfaces by light microscopy.

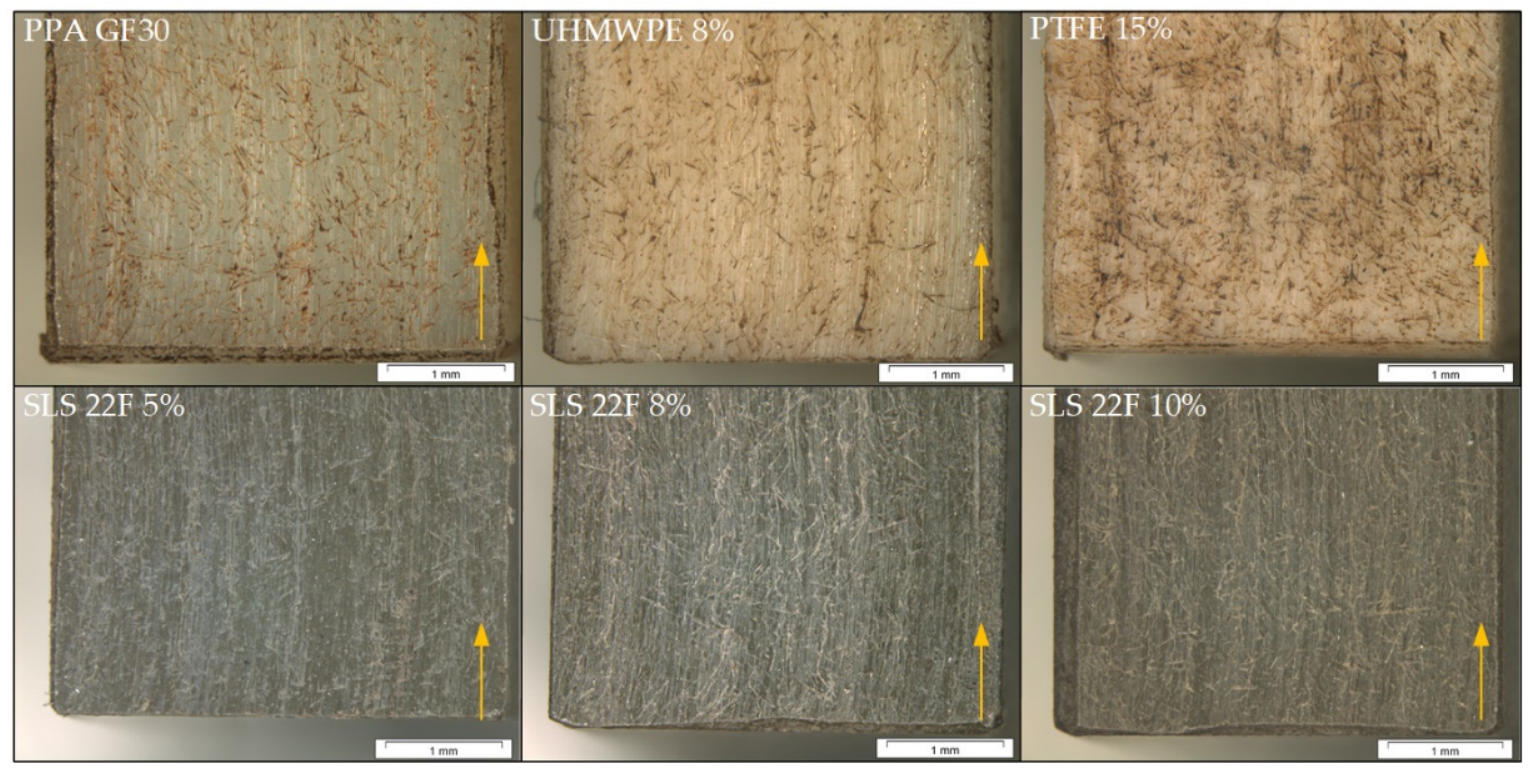

Figure 10. Damage pictures $(40 \times)$. Arrows indicate the moving direction.

Two main observations in Figure 10 can be made: first, the high content $(30 \%)$ of glass fibres dominates in all six running surfaces after testing, and second, a clear colourbased difference between the upper and lower row of pictures is visible. This difference is attributed to the grey coloured SLS 22F solid lubricant. Furthermore, all six surfaces show no severe wear process and quite comparable surface structures, which is in agreement with the minimal wear rates represented in Figure 9. In general, all three solid lubricants (PTFE, UHMWPE and SLS 22F) are based on the same lubrication mechanism, namely the slipping of the layers. This is caused by the strong intralayer forces but comparably weak interlayer bonding strength which results in a slipping evoked by shear forces. The investigated solid lubricants differ in the bonding mechanism which, for metal sulphidic fillers, count as structural lubricants due to the lattice structure and polymer-based solid lubricants belonging to mechanical lubricants. This is due to the weak van der Waals forces without a lattice structure [5,12,36].

To obtain in-depth information about the qualitative distribution of the glass fibres and solid lubricants at the running surface of the samples, SEM/EDX analyses were performed. Stacked mappings of the elements are shown in Figure 11.

At first sight, the EDX analysis shows a clear difference between the $15 \%$ and $30 \%$ glass fibre content samples and their visible fibre orientation at the running surface (cp. Figures 8 and 11). The fibre structure is, in all variants, prominently visible, except for SLS 22F $10 \%$ also compared in the light microscopic pictures (see Figure 10). A fine phosphor (P) mapping dominates, indicating the presence of SLS 22F. This element-based information gives a good added value to the basic light microscopy pictures. 


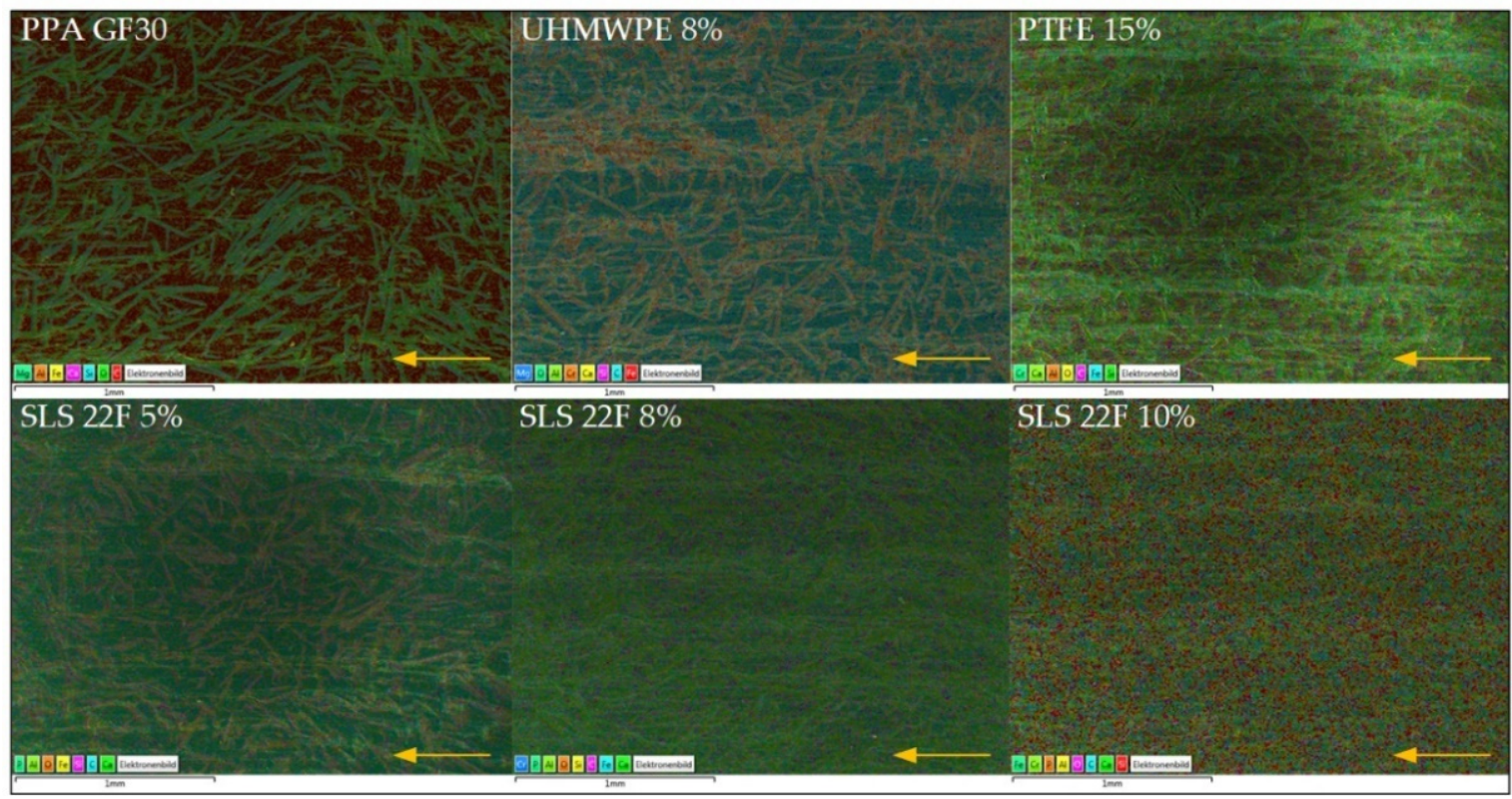

Figure 11. EDX micrographs $(100 \times)$ of all PPA GF30 systems with different filling degrees and sampling position normal to the processing direction. Arrows indicate the moving direction.

\subsection{Comparison of SLS 22 in Different Matrices}

For a better analysis of the metal sulphide filler influence, i.e., both variations of SLS 22 with different filling degrees (5 and 10\%), on the tribological properties, the results from the different matrix materials are given in Figure 12. All results show the investigations in processing direction. As discussed previously in Section 3.3, SLS 22 evokes a decrease in the wear rate for all matrix materials in processing direction.

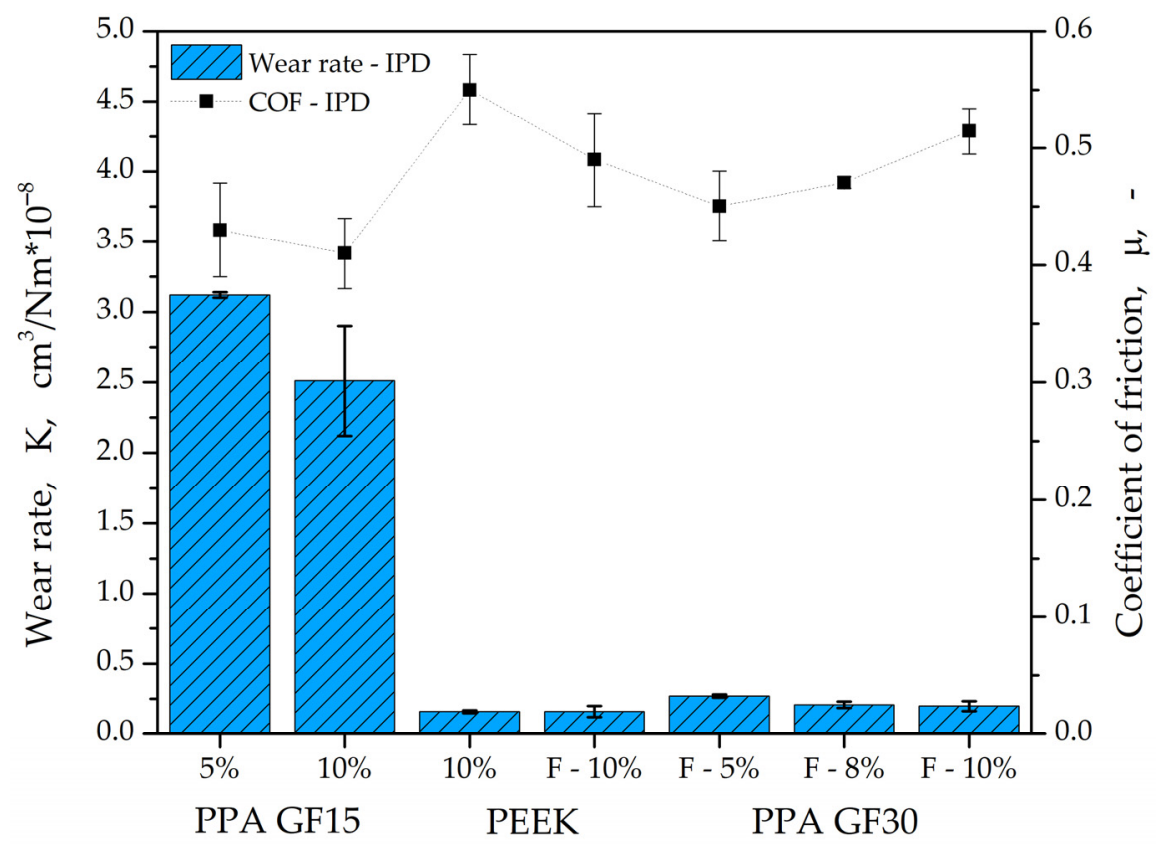

Figure 12. Wear rates and coefficients of friction in the processing direction for different matrix materials as a function of the SLS 22 (5 and 10\%) and SLS 22F (F-5 and F-10\%) content.

Considering only the matrix materials, the filling degree seems to only have an influence on the wear rate for PPA GF15, which results from slide layers which can evolve more easily with more solid lubricant available in the sample. PEEK shows no considerable 
change in the wear rate with a finer filler particle size, but a decrease in the CoF is observed, evoked by a better distribution of the filler particles. PPA GF30 shows, similar to PEEK, a wear rate independent of the filling degree, but an increase in CoF with higher filling degrees. It is interesting to mention that CoF increases for a rising SLS 22F filling degree in a PPA GF30 matrix. One possible explanation could be the higher heat conductivity due to the higher filling degree (see Table 3).

Table 3. Material combinations, respective filling degrees (FD) and heat conductivity (HC).

\begin{tabular}{ccccccccc}
\hline Material & $\begin{array}{c}\text { FD } \\
{[\mathbf{w} \%]}\end{array}$ & $\begin{array}{c}\text { HC } \\
{[\mathbf{W} / \mathbf{m K}]}\end{array}$ & Material & $\begin{array}{c}\text { FD } \\
{[\mathbf{w} \%]}\end{array}$ & $\begin{array}{c}\text { HC } \\
{[\mathbf{W} / \mathbf{m K}]}\end{array}$ & Material & $\begin{array}{c}\text { FD } \\
{[\mathbf{w} \%]}\end{array}$ & $\begin{array}{c}\text { HC } \\
{[\mathbf{W} / \mathbf{m K}]}\end{array}$ \\
\hline PEEK & & 0.287 & PPA GF15 & & 0.312 & PPA GF30 & & 0.332 \\
SLS 22 & 10 & 0.289 & SLS 22 & 5 & 0.322 & SLS 22F & 5 & 0.386 \\
SLS 22F & 10 & 0.289 & SLS 22 & 10 & 0.334 & SLS 22F & 10 & 0.410 \\
\hline
\end{tabular}

Since the PPA GF30 glass transition temperature $\left(125^{\circ} \mathrm{C}\right)$ is easily reached during friction contact due to frictional heating, a higher heat conductivity would lead to faster heat dissipation. This means that the sample with higher heat conductivity would not soften (or soften less) due to the glass transition; hence, the solid lubricant would not be exposed (or would be less exposed) by such a softening effect [3,37].

These overall results of the friction coefficient can be traced back to the hardness of the materials. Since PEEK and PPA with $30 \mathrm{wt} . \%$ glass fibres are harder than PPA with $15 \mathrm{wt} . \%$, these matrix systems are able to bear more load than the solid lubricant itself (cp. Table 1). This would result in less lubricating effects of the harder samples, namely PEEK and PPA GF30, which therefore represents a CoF of the matrix and not in combination with the solid lubricant $[38,39]$. For both PPAs, the content of the glass fibres also has an impact, but for the $30 \mathrm{wt} . \%$ filling degree, the stiffening effect seems to be more dominant than the abrasive effect caused by exposure to solid lubricants. The higher stiffness can be correlated to the heat deflection temperature, which increases with fibre reinforcement [7,40,41].

Comparing the CoF of PPA GF15 and GF30, it could be considered that the fibre content has a significant impact. Yet, taking only the wear height into account, PPA GF15 was worn more than the surface layer. This is the same for PEEK, where the wear rate indicates a wear height of approximately $300 \mu \mathrm{m}$. With this wear height, no gliding film can be formed, which therefore results in higher CoFs than PPA GF15 and a wear height of approximately $1000 \mu \mathrm{m}$. The difference in the wear height is also visible in Figure 13 where only PPA GF15 shows the typical gliding layers and the other two matrix materials are hardly worn.

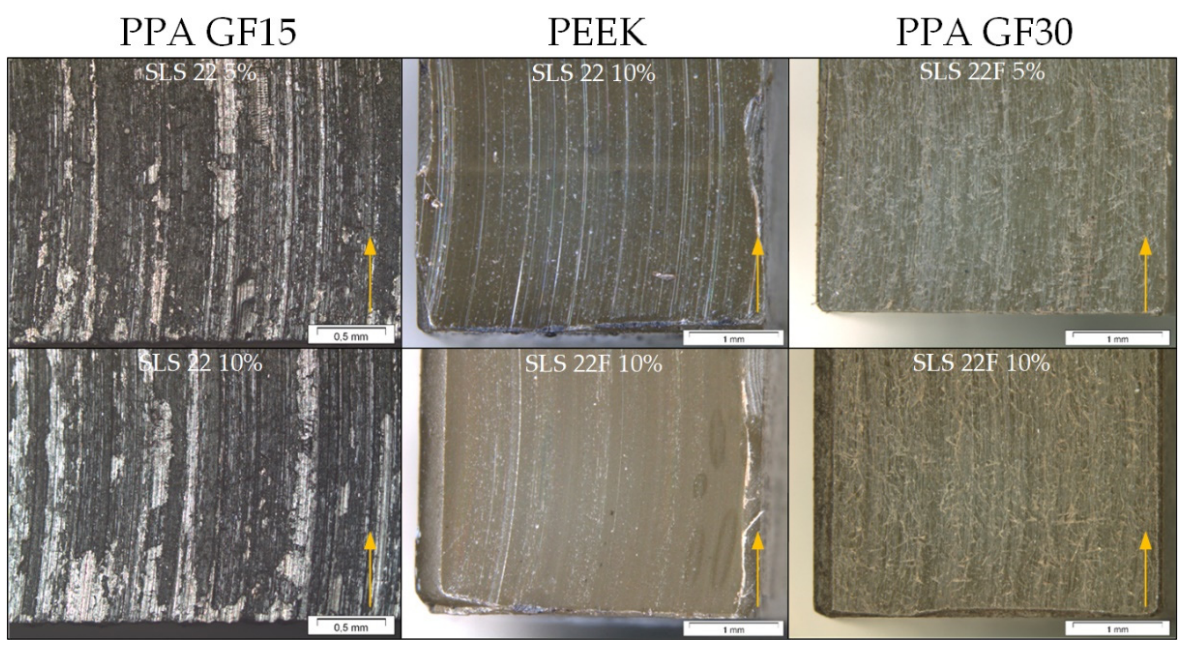

Figure 13. Damage pictures of PPA GF15 $(50 \times)$, PEEK and PPA GF30 $(40 \times)$ for SLS 22 and SLS 22F with $5 \%$ and $10 \%$ filling degrees. 


\section{Conclusions}

The tribological properties of PEEK and PPA-based compounds and the influence of alternative metal sulphide solid lubricants in combination with different glass fibre contents were investigated in this study. A beneficial effect of adding metal sulphide filler systems to different matrices on tribological performance is shown. Specifically, both variations of SLS 22 showed a constant enhancement with low scattering. In this case, a $25 \%$ reduction in the wear rate compared to MOS XF was reached for PEEK compounds. The investigations highlighted that this filler system is independent of the sampling position and, furthermore, almost independent of the filling degree of the matrix. In addition, analysis of PPA reveals that the increase in glass fibre content shows an additional improvement in wear properties and that SLS 22 works well with glass fibres. It should be kept in mind that every tribological system has an optimum point, and in this study, the results are presented for a model PoD setup. In general, too high filling degrees will lead to an unstable matrix and an insufficient dispersion of the agglomerates within the matrix [12,26-28]. Furthermore, the matrix-filler-bonding has a crucial impact on tribological behaviour and it is also influenced by the processing. Nevertheless, this solid lubricant system seems to be a promising alternative to common solid lubricants, such as $\mathrm{MoS}_{2}$ or PTFE, and it paves the way for new applications.

Author Contributions: Conceptualization, T.S. and A.H.; methodology, A.H.; validation, T.S., A.H. and F.G.; formal analysis, A.H.; investigation, T.S.; writing-original draft preparation, T.S. and A.H.; writing-review and editing, A.H.; review, C.K., L.H. and F.G.; visualization, T.S. and A.H.; supervision, F.G.; project administration, A.H. All authors have read and agreed to the published version of the manuscript.

Funding: The recent research work was performed at the Polymer Competence Center Leoben $\mathrm{GmbH}$ (PCCL, Austria) within the framework of the COMET-program of the Federal Ministry for Transport, Innovation and Technology and the Federal Ministry of Digital and Economic Affairs (FFG: 854178).

Conflicts of Interest: The authors declare no conflict of interest.

\section{References}

1. Friedrich, K. Friction and Wear of Polymer Composites; Elsevier: Amsterdam, The Netherlands, 1986; ISBN 0-444-42524-1.

2. Mang, T.; Bobzin, K.; Bartels, T. Industrial Tribology: Tribosystems, Friction, Wear and Surface Engineering, Lubrication; Wiley-VCH: Weinheim, Germany, 2010; ISBN 978-3-527-32057-8.

3. Bruce, R.W. Handbook of Lubrication and Tribology, Volume II; CRC Press: Boca Raton, FL, USA, 2012; ISBN 978-1-4200-6909-9.

4. Glasscock, D.; Atolino, W.; Kozielski, G.; Martens, M. High Performance Polyamides Fulfill Demanding Requirements for Automotive Thermal Management Components. 2008.

5. Sinha, S.K.; Briscoe, B.J. Polymer Tribology; Imperial College Press: London, UK; Distributed by World Scientific: London, UK; Singapore; Hackensack, NJ, USA, 2009; ISBN 1848162022.

6. Stachowiak, G.W.; Batchelor, A.W. Engineering Tribology, 4th ed.; Elsevier/Butterworth-Heinemann: Oxford, UK, 2014; ISBN 0123970474.

7. Wypych, G. Handbook of Fillers, 4th ed.; Chem Tec Publishing: Toronto, ON, Canada, 2016; ISBN 978-1-927885-10-9.

8. Birkhofer, H.; Kümmerle, T. Die Tribologie von Festschmierstoffen. In Feststoffgeschmierte Wälzlager; Birkhofer, H., Kümmerle, T., Eds.; Springer: Berlin/Heidelberg, Germany, 2012; pp. 15-53, ISBN 978-3-642-16796-6.

9. Menezes, P.L.; Nosonovsky, M.; Ingole, S.P.; Kailas, S.V.; Lovell, M.R. (Eds.) Tribology for Scientists and Engineers: From Basics to Advanced Concepts; Springer: New York, NY, USA, 2013; ISBN 978-1-4614-1945-7.

10. Kim, S.S.; Shin, M.W.; Jang, H. Tribological properties of short glass fiber reinforced polyamide 12 sliding on medium carbon steel. Wear 2012, 274, 34-42. [CrossRef]

11. Li, D.-X.; You, Y.-L.; Deng, X.; Li, W.-J.; Xie, Y. Tribological properties of solid lubricants filled glass fiber reinforced polyamide 6 composites. Mater. Des. 2013, 46, 809-815. [CrossRef]

12. Rothon, R. Fillers for Polymer Applications; Springer International Publishing: Cham, Germany, 2017.

13. Cirino, M.; Friedrich, K.; Pipes, R.B. The Effect of Fiber orientation on the abrasive wear behavior of polymer composite materials. Wear 1988, 121, 127-141. [CrossRef]

14. Reinicke, P.; Friedrich, K.; Beier, W.; Liebald, R. Tribological properties of SiC and C-fiber reinforced glass matrix composites. Wear 1999, 225, 1315-1321. [CrossRef] 
15. Song, F.; Wang, Q.; Wang, T. Effects of glass fiber and molybdenum disulfide on tribological behaviors and PV limit of chopped carbon fiber reinforced Polytetrafluoroethylene composites. Tribol. Int. 2016, 104, 392-401. [CrossRef]

16. Unal, H.; Mimaroglu, A. Comparison of tribological performance of PEEK, UHMWPE, glass fiber reinforced PTFE and PTFE reinforced PEI composite materials under dry and lubricated conditions. J. Polym. Eng. 2012, 32, 349-354. [CrossRef]

17. Davim, J.P.; Cardoso, R. Effect of the reinforcement (carbon or glass fibres) on friction and wear behaviour of the PEEK against steel surface at long dry sliding. Wear 2009, 266, 795-799. [CrossRef]

18. Bahadur, S.; Gong, D. The action of fillers in the modification of the tribological behavior of polymers. Wear 1992, 158, 41-59. [CrossRef]

19. Schwartz, C.J.; Bahadur, S. The role of filler deformability, filler-polymer bonding, and counterface material on the tribological behavior of polyphenylene sulfide (PPS). Wear 2001, 251, 1532-1540. [CrossRef]

20. Brooks, R. Injection Molding Based Techniques. Compr. Compos. Mater. 2000, 2, 999-1028. [CrossRef]

21. Papathanasiou, T.D.; Guell, D. Flow Induced Alignment in Composite Materials; Woodhead Publishing Limited: Cambridge, UK, 1997; ISBN 855732548.

22. Bechara, A.; Kollert, S.; Onken, J.; Ramírez, D.; Osswald, T. Effects of fountain flow on fiber orientation and distribution in fiber filled polymers during mold filling. In Proceedings of the 72nd Annual technical conference of the Society of Plastic Engineers (ANTEC), Las Vegas, NV, USA, 28-30 April 2014.

23. Kastner, J.; Salaberger, D.; Plank, B. High resolution X-ray computed tomography of fibre and particle filled polymers. In Proceedings of the 18th World Conference on Nondestructive Testing, Durban, South Africa, 16-20 April 2012.

24. Zalaznik, M.; Kalin, M.; Novak, S.; Jakša, G. Effect of the type, size and concentration of solid lubricants on the tribological properties of the polymer PEEK. Wear 2016, 364, 31-39. [CrossRef]

25. DIN EN ISO 25178-1:2016-12. Geometrische Produktspezifikation_(GPS)_Oberflächenbeschaffenheit: Flächenhaft_Teil_1: Angabe von Oberflächenbeschaffenheit (ISO_25178-1:2016); Deutsche Fassung EN_ISO_25178-1:2016; Beuth Verlag GmbH: Berlin, Germany, 2016.

26. Pesche, R.; Bossis, G.; Meunier, A. Simulation of Particle Segregation in A Bidisperse Suspension. In Proceedings of the Third International Conference on Multiphase Flow, Lyon, France, 8-12 June 1998.

27. Drijer, I.; Schroën, K. Modelling Shear Induced Diffusion Based Particle Segregation: A Basis for Novel Separation Technology. Appl. Sci. 2018, 8, 1008. [CrossRef]

28. Reddy, M.M.; Singh, A. Shear-induced particle migration and size segregation in bidisperse suspension flowing through symmetric T-shaped channel. Phys. Fluids 2019, 31, 53305. [CrossRef]

29. Budinski, K.G. Friction, Wear, and Erosion Atlas; Taylor and Francis: Hoboken, NJ, USA, 2013; ISBN 9781466587267.

30. Ye, J.; Khare, H.S.; Burris, D.L. Transfer film evolution and its role in promoting ultra-low wear of a PTFE nanocomposite. Wear 2013, 297, 1095-1102. [CrossRef]

31. Chawla, K.K. Glass Fibers. In Reference Module in Materials Science and Materials Engineering; Elsevier: Amsterdam, The Netherlands, 2001; pp. 3541-3545. [CrossRef]

32. Cevahir, A. Glass fibers. In Fiber Technology for Fiber-Reinforced Composites; Woodhead Publishing: Duxford, UK, 2017 ; pp. 99-121. [CrossRef]

33. Martynova, E.; Cebulla, H. Glass Fibers. In Inorganic and Composite Fibres: Production, Properties, and Applications; Woodhead Publishing: Duxford, UK, 2018; pp. 131-163. [CrossRef]

34. Hu, H.; Liu, Y. High modulus, high tenacity yarns. In Technical Textile Yarns; Woodhead Publishing: Sawston, UK, 2010; pp. 329-386. [CrossRef]

35. Sung, N.; Suh, N. Effect of fiber orientation on friction and wear of fiber reinforced polymeric composites. Wear 1979, 53, $129-141$.

36. Wang, Q.J.; Chung, Y.-W. Encyclopedia of Tribology; Springer: Boston, MA, USA, 2013; ISBN 978-0-387-92896-8.

37. Bhushan, B. Modern Tribology Handbook; CRC Press: Boca Raton, FL, USA, 2001.

38. Grün, F.; Gódor, I.; Sailer, W.; Gänser, H.-P. Simulation of tribological functionality of heterogeneous tribomaterials. Tribol. Int. 2012, 46, 119-127. [CrossRef]

39. Czichos, H.; Habig, K.-H. Tribologie-Handbuch: Reibung und Verschleiß, 3rd ed.; Viewig+Teubner Verlag/Springer Fachmedien, Wiesbaden GmbH: Berlin/Heidelberg, Germany, 2020; ISBN 978-3-8348-0017-6.

40. Bargel, H.-J.; Schulze, G. Werkstoffkunde; Springer: Berlin/Heidelberg, Germany, 2012; ISBN 978-3-642-17716-3.

41. Bonnet, M. Kunststoffe in der Ingenieuranwendung: Verstehen und Zuverlässig Auswählen, 1st ed.; Vieweg + Teubner Verlag/GWV Fachverlage GmbH Wiesbaden: Wiesbaden, Germany, 2009; ISBN 9783834803498. 